\title{
Lewis Acid/Hexafluoroisopropanol: A Promoter System for Selective ortho-C-Alkylation of Anilines with Deactivated Styrene Derivatives and Unactivated Alkenes
}

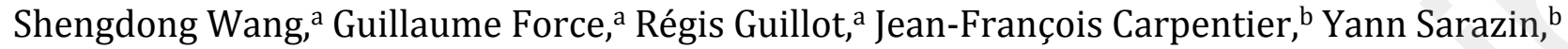 \\ Christophe Bour, ${ }^{a}$ Vincent Gandon*,a,c and David Lebœuf*,d \\ a Institut de Chimie Moléculaire et des Matériaux d'Orsay (ICMMO), CNRS UMR 8182, Université Paris-Saclay, Bâtiment \\ 420, 91405 Orsay, France. \\ b Univ. Rennes, CNRS UMR 6226, Institut des Sciences Chimiques de Rennes (ISCR), 35000 Rennes, France. \\ c.Laboratoire de Chimie Moléculaire (LCM), CNRS UMR 9168, Ecole Polytechnique, Institut Polytechnique de Paris, route \\ de Saclay, 91128 Palaiseau cedex, France. \\ d Institut de Science et d'Ingénierie Supramoléculaires (ISIS), CNRS UMR 7006, Université de Strasbourg, 8 allée Gaspard \\ Monge, 67000 Strasbourg, France. \\ KEYWORDS alkenes, anilines, hexafluoroisopropanol, Lewis acid, ortho-C-alkylation
}

\begin{abstract}
Aniline derivatives are frequently encountered in molecules of industrial relevance such as dyes or antioxidants, which make the development of synthetic methods for the functionalization of these privileged structures highly sought-after. A general protocol for the hydroarylation of electronically diverse alkenes with anilines would be ideal to provide densely functionalized compounds. Yet, this transformation has been underexplored compared to more traditional hydroarylation of unactivated alkenes because of the significant challenges associated with the control of the selectivity and its substrate tolerance. Herein, we describe a selective, versatile and user-friendly ortho-C-alkylation of anilines with alkenes that hinges on the beneficial combination of a Lewis acid (Ca(II)) and hexafluoroisopropanol as a solvent. This protocol allows for the extension of this transformation to highly deactivated styrenes and demonstrates a remarkable improved reactivity regarding aliphatic alkenes, styrene derivatives and dienes. In addition, DFT computations were performed which, combined with experimental observations, suggest a nearly concerted mechanism that impart the ortho-selectivity.
\end{abstract}

Diarylamines, and generally simple anilines, are prevalent building blocks in organic synthesis. They offer a wide variety of applications, including pharmaceuticals, agrochemicals, and functional organic materials. ${ }^{1}$ Besides, they can be rapidly converted into acridinium derivatives, ${ }^{2}$ which have emerged as powerful catalysts for photoredox transformations. ${ }^{3}$ Within this context, the identification of synthetic methods to increase the molecular complexity and diversity of these compounds has been thoroughly investigated over the last decades. Among them, the hydroarylation of unactivated alkenes with anilines represents arguably an ideal process: an atom- and stepeconomic transformation featuring feedstock alkenes and anilines to form key $\mathrm{C}-\mathrm{C}$ bonds in an efficient manner. ${ }^{4}$ Despite many studies outlined in Scheme $1,^{5-7}$ the intrinsic limitations associated with this transformation have still to be addressed, including its unpredictable selectivity (orthoC alkylation/para-C alkylation/hydroamination), its incompatibility with highly deactivated styrenes and $\mathrm{N}$ (alkyl or aryl) diarylamines and its limited reactivity regarding aliphatic alkenes. In particular, the dearth of reports regarding highly deactivated styrenes ${ }^{8}$ that incorporate strong electron-withdrawing groups is detrimental to discovering new applications, as such substrates may impart original properties to the compounds prepared through non-covalent interactions ( $\pi$ anion, lone pair- $\pi$ or $\pi-\pi$ interactions). ${ }^{9}$ In the realm of hydroarylation of unactivated alkenes, a traditional approach involves the use of a Lewis or Brønsted acid, which typically triggers the formation of a stabilized carbocation species and a subsequent trapping by (hetero)arene nucleophiles. ${ }^{4}$ Yet, this strategy often leads to both ortho- and para-products, limiting its applicability. The problem becomes even more pronounced in the case of anilines, which can also undergo hydroamination reactions (Schemes 1a-1c). ${ }^{10}$ To account for the formation of the ortho-alkylated product, Beller and coworkers alluded to a concerted mechanism that would differ from that of a typical proton-catalyzed hydroarylation (Scheme 1c). ${ }^{6 a}$ However, in the case of Lewis and Brønsted acid-based strategies, the transformation led to uneven selectivities between ortho-C alkylation and hydroamination depending on the promoter system used (from 1:0 to $0: 1$ ), ${ }^{6 a, 6 c-61,6 n}$ suggesting competing reaction pathways. To date, the iridium-catalyzed enantioselective ortho-alkylation of acetanilides described by the group of Bower can be considered as a reference in terms of selectivity (Scheme 1f); ${ }^{60,6 t}$ yet, no highly deactivated styrene was investigated, a specific directing-group was required, and tertiary anilines were incompatible with the reaction conditions. In 
Scheme 1. Hydroarylation and hydroamination of olefins with aniline derivatives.
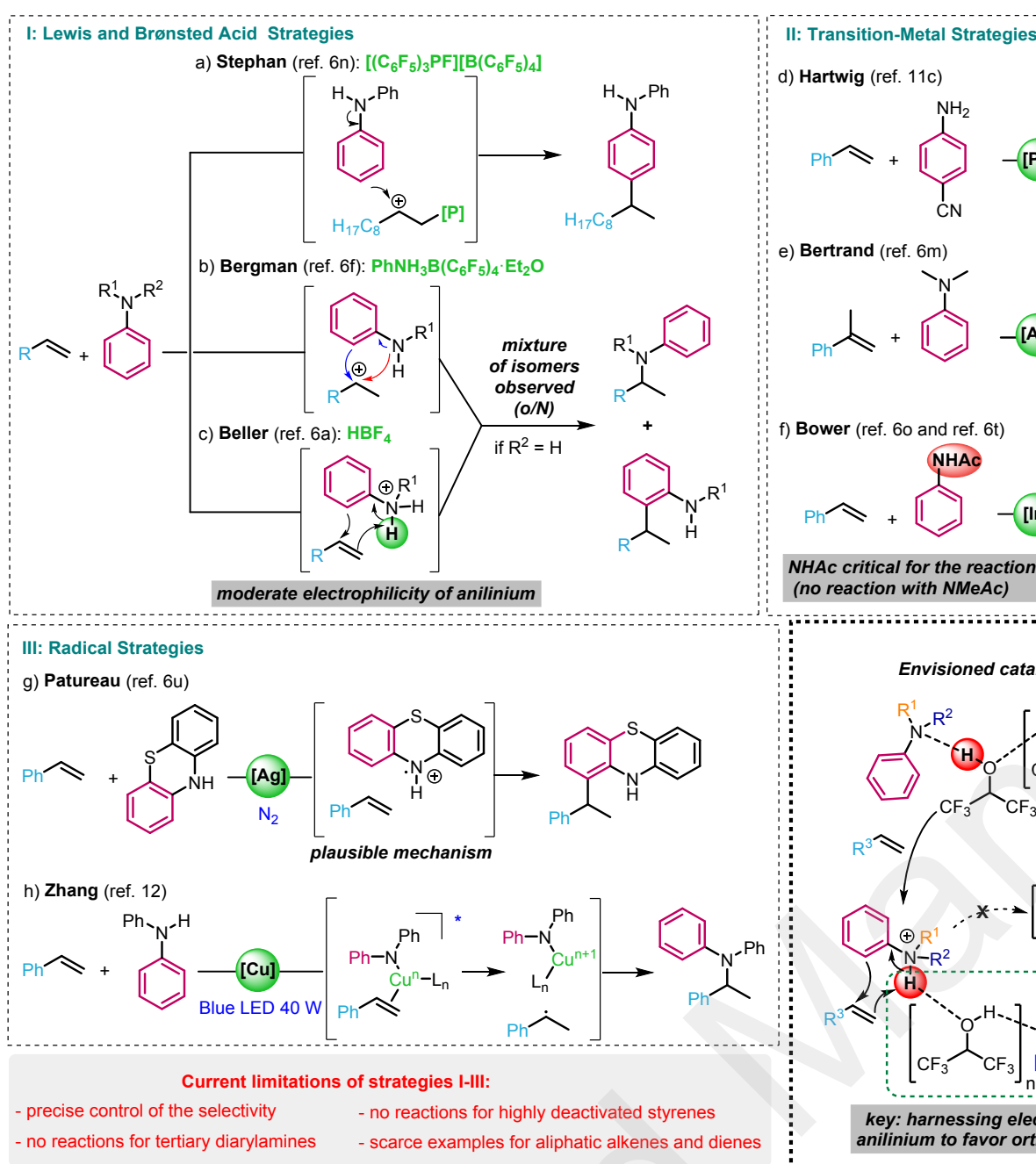

Bertrand (ref. $6 \mathrm{~m}$ )

f) Bower (ref. 6o and ref. 6t)

contrast, transition-metal-catalyzed reactions are more prone to produce hydroamination adducts ${ }^{11}$ or give rise to para-selectivity in the absence of directing groups (Schemes 1d-1e). ${ }^{6 m, 6 q}$ Visible-light photoredox protocols are curbed with similar limitations (Schemes $1 \mathrm{~g}-1 \mathrm{~h}$ ). ${ }^{12}$

Our recent studies demonstrated that the use of HFIP as a solvent ${ }^{13}$ paired with a Lewis or Brønsted acid enables the activation of highly unreactive olefins. ${ }^{8 f, 14}$ Conceptually, the role of the catalyst in these examples is not to directly activate the nucleophile or the electrophile, but, instead, to augment the acidity of a H-bond network of HFIP molecules. ${ }^{8 f, 14 a}$ In search of a reliable and selective ortho-Calkylation of anilines with olefins and inspired by the work of Beller, we reasoned that, under highly acidic conditions, anilines would provide an anilinium cation, which could react through a 6-membered transition state to generate the targeted ortho-alkylated product exclusively. This is where the use of HFIP would be paramount for the success of the transformation as it may sufficiently harness the acidity of the anilinium to even react with highly deactivated substrate, in contrast with the use of common solvents. ${ }^{15}$ Importantly, the strategy could be applied irrespective of the nature of the aniline (primary, secondary or tertiary). Additionally, since the aniline would act as a buffer, even

dienes and styrene derivatives, which typically generate oligomers in HFIP, ${ }^{16}$ could be tolerated. Herein, we disclose our findings regarding this transformation with a special emphasis on highly deactivated styrenes and their synthetic applications. This approach provides an amenable and broadly applicable method to break the stalemate on the selective ortho-C-alkylation of anilines. The mechanistic considerations are further supported by DFT computations. Moreover, this study shows how the nature of the substrates can dictate the ortho/para selectivity. ${ }^{17}$

At the outset, we examined the feasibility of this concept by investigating the inherent reactivity of highly deactivated 4cyanostyrene 1a with diphenylamine $\mathbf{2 a}^{\text {6u }}$ (4 equiv.) in the presence of the promoter system that we previously described for hydrofunctionalizations: $\mathrm{Ca}\left(\mathrm{NTf}_{2}\right)_{2} / n \mathrm{Bu}_{4} \mathrm{NPF}_{6}$ $(20 \mathrm{~mol} \%)^{18}$ in HFIP $(0.2 \mathrm{M})$ (Table 1$)$. With respect to this system, the role of the ammonium salt of weakly coordinating hexafluorophosphate is to promote an anion metathesis to form the heteroleptic salt $\mathrm{Ca}\left(\mathrm{NTf}_{2}\right)\left(\mathrm{PF}_{6}\right)$, which is more prone to activate the H-bond network of HFIP than the sole $\mathrm{Ca}\left(\mathrm{NTf}_{2}\right)_{2} \cdot{ }^{19}$ Although the reaction required a prolonged heating at $120{ }^{\circ} \mathrm{C}$ for $4 \mathrm{~d}$ to proceed to full conversion, the targeted compound 3aa was obtained as a sole product in an excellent yield of $92 \%$ (entry 1). The 
structure of 3aa was further confirmed by X-ray analysis (Figure 1). Reactions with reduced number of equivalents of diphenylamine 2a still yielded 3aa, albeit in lower yields (entries 2-4). ${ }^{20}$ On the other hand, we found that the reaction was significantly affected by the catalyst loading as the yield decreased to $55 \%$ in the presence of $10 \mathrm{~mol} \%$ of catalyst (entry 5). Importantly, no reaction was observed by conducting the transformation in common solvents (entries 6-8), while 1a remained intact. Besides, reactions in solvent mixtures to decrease the amount of HFIP employed gave inferior results (entries 9-11). While reactions in the presence of $\mathrm{Ca}\left(\mathrm{NTf}_{2}\right)_{2}$ occurred with the highest yields, $\mathrm{Ca}\left(\mathrm{NTf}_{2}\right)_{2}$ is not pivotal in the process; reactions in the presence of a wide series of Lewis and Brønsted acids also furnished product 3aa in high yields (55-87\%) (entries 1217), indicating that HFIP is the true cornerstone of the reaction. Given the results obtained, $\mathrm{Ca}\left(\mathrm{NTf}_{2}\right)_{2}$ has the major advantage to be easy to handle when compared to $\mathrm{HNTf}_{2}$, which is highly hygroscopic and becomes rapidly deliquescent. Of note, the sole presence of HFIP is not sufficient to mediate the reaction (entry 18). The robustness of this reaction was also evaluated on a scale-up experiment ( $5 \mathrm{mmol}$ ) and 3aa could be synthesized on a $1.33 \mathrm{~g}$ scale $(89 \%)$.

Table 1. Reaction optimization for the formation of diarylethane 3aa. ${ }^{[a]}$

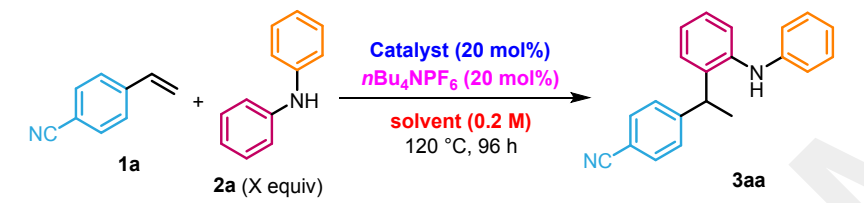

\begin{tabular}{|c|c|c|c|c|}
\hline entry & catalyst & solvent & $\mathrm{x}$ & yield [\%] $]^{[\mathrm{d}]}$ \\
\hline 1 & $\mathrm{Ca}\left(\mathrm{NTf}_{2}\right)_{2}$ & HFIP & 4 & 92 \\
\hline 2 & $\mathrm{Ca}\left(\mathrm{NTf}_{2}\right)_{2}$ & HFIP & 3 & 89 \\
\hline 3 & $\mathrm{Ca}\left(\mathrm{NTf}_{2}\right)_{2}$ & HFIP & 2 & 78 \\
\hline 4 & $\mathrm{Ca}\left(\mathrm{NTf}_{2}\right)_{2}$ & HFIP & 1 & 75 \\
\hline $5^{[b]}$ & $\mathrm{Ca}\left(\mathrm{NTf}_{2}\right)_{2}$ & HFIP & 4 & 55 \\
\hline 6 & $\mathrm{Ca}\left(\mathrm{NTf}_{2}\right)_{2}$ & 1,2-DCE & 4 & NR \\
\hline 7 & $\mathrm{Ca}\left(\mathrm{NTf}_{2}\right)_{2}$ & toluene & 4 & NR \\
\hline 8 & $\mathrm{Ca}\left(\mathrm{NTf}_{2}\right)_{2}$ & $\mathrm{MeNO}_{2}$ & 4 & NR \\
\hline 9 & $\mathrm{Ca}\left(\mathrm{NTf}_{2}\right)_{2}$ & 1,2-DCE/HFIP (3:1) & 4 & 43 \\
\hline 10 & $\mathrm{Ca}\left(\mathrm{NTf}_{2}\right)_{2}$ & toluene/HFIP (3:1) & 4 & 60 \\
\hline 11 & $\mathrm{Ca}\left(\mathrm{NTf}_{2}\right)_{2}$ & $\mathrm{MeNO}_{2} / \mathrm{HFIP}(3: 1)$ & 4 & 23 \\
\hline $12^{[c]}$ & $\mathrm{HNTf}_{2}$ & HFIP & 4 & 87 \\
\hline $13^{[c]}$ & Hотf & HFIP & 4 & 87 \\
\hline 14 & $\mathrm{Sc}(\mathrm{OTf})_{3}$ & HFIP & 4 & 80 \\
\hline 15 & $\mathrm{Cu}(\mathrm{OTf})_{2}$ & HFIP & 4 & 55 \\
\hline 16 & $\mathrm{Bi}(\mathrm{OTf})_{3}$ & HFIP & 4 & 83 \\
\hline 17 & $\operatorname{Al}(\mathrm{OTf})_{3}$ & HFIP & 4 & 85 \\
\hline 18 & - & HFIP & 4 & NR \\
\hline
\end{tabular}

[a] Reactions performed in a sealed tube. [b] Reaction in the presence of $\mathrm{Ca}\left(\mathrm{NTf}_{2}\right)_{2}(10 \mathrm{~mol} \%)$ and $n \mathrm{Bu}_{4} \mathrm{NPF}_{6}(10 \mathrm{~mol} \%)$. [c] Reaction in the absence of $n \mathrm{Bu}_{4} \mathrm{NPF}_{6}$. [d] Yields of isolated 3aa. NR = no reaction.

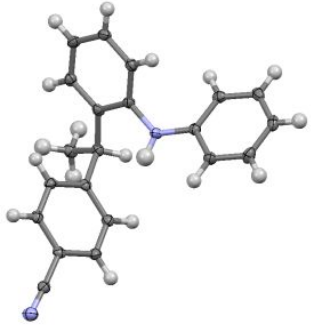

Figure 1. ORTEP drawing of compound 3aa. Thermal ellipsoids are shown at $50 \%$ probability level.

With the identified reaction conditions, we sought to explore the generality of the protocol with a large range of alkene and aniline derivatives (Scheme 2). Initially, we focused our efforts on the reactivity of different styrene derivatives bearing distinct electronic properties and substitution patterns. The reaction proved to be compatible with a large variety of strong electron-withdrawing groups to yield the corresponding products in good to excellent yields (3aa-3ga and 3ka-3na, 56-95\%). Substituents at ortho-, meta- and para-positions were well tolerated. However, in the case of even more deactivated substrates such as $1 \mathrm{~m}$ and $1 \mathrm{n}$, the reaction required $6 \mathrm{~d}$ for the styrene to be fully consumed. The reaction could also be expanded to styrenes bearing moderate electron-withdrawing groups (1h and 1i) and even unsubstituted styrene $\mathbf{1 j}$, which is typically prone to undergo oligomerization in HFIP, ${ }^{16}$ confirming the role of buffer of the amine in the reaction to preclude the side-process. These transformations could be conducted under milder reaction conditions $\left(20^{\circ} \mathrm{C}\right)$, which represents a notable improvement when compared to previous reports that required higher temperatures (up to $\left.160{ }^{\circ} \mathrm{C}\right) .^{6}$ Furthermore, aliphatic alkenes (1p-1r) were competent substrates for the reactions, forming the products in $80-95 \%$ yields. Even a substrate incorporating an additional functional group (1) that may engage in an intramolecular process reacted in a target fashion. It should be emphasized that, in all reactions studied, no products arising from the isomerization of the double bond were observed. The reaction was also not limited to monosubstituted styrenes: both $\alpha$ - and $\beta$-methylstyrenes 1 s and 1t afforded the products in $89 \%$ and $63 \%$ yields, respectively. Reactions of cyclic alkenes such as norbornene $\mathbf{1 u}$ and 1,3-cyclohexadiene $\mathbf{1 v}$ gave also excellent results ( $88 \%$ and $87 \%$ yields). Finally, we examined the reactivity of hindered styrenes such as $(E)$-stilbene $\mathbf{1 w}$, which led to compound 3wa in a moderate yield (35\%). ${ }^{21}$

Next, we evaluated a broad range of diarylamines in a model reaction with 4-cyanostyrene 1a. Initially, we investigated symmetrical diarylamines (3ab-3ah). In addition to diphenylamine $\mathbf{2 a}$, this catalytic process was applied to prepare a number of frameworks of interest such as phenothiazine (3ab, 63\%), phenoxazine (3ac, 72\%), dihydroacridine (3ad, 85\%) or iminodibenzyl (3ae, 90\%). One exception was carbazole 2f, which furnished both ortho- and para-products in a combined yield of $84 \%(o / p$ 67:33). An important feature of this protocol is also the use of dissymmetrical diarylamines. We noticed that, by relying on the electronic properties of the aryl rings with electrondonating or electron- withdrawing groups, it was possible to execute the reaction with a good control of the selectivity, 
Scheme 2. Scope and limitations of the C-alkylation of anilines with olefins. ${ }^{[a]}$
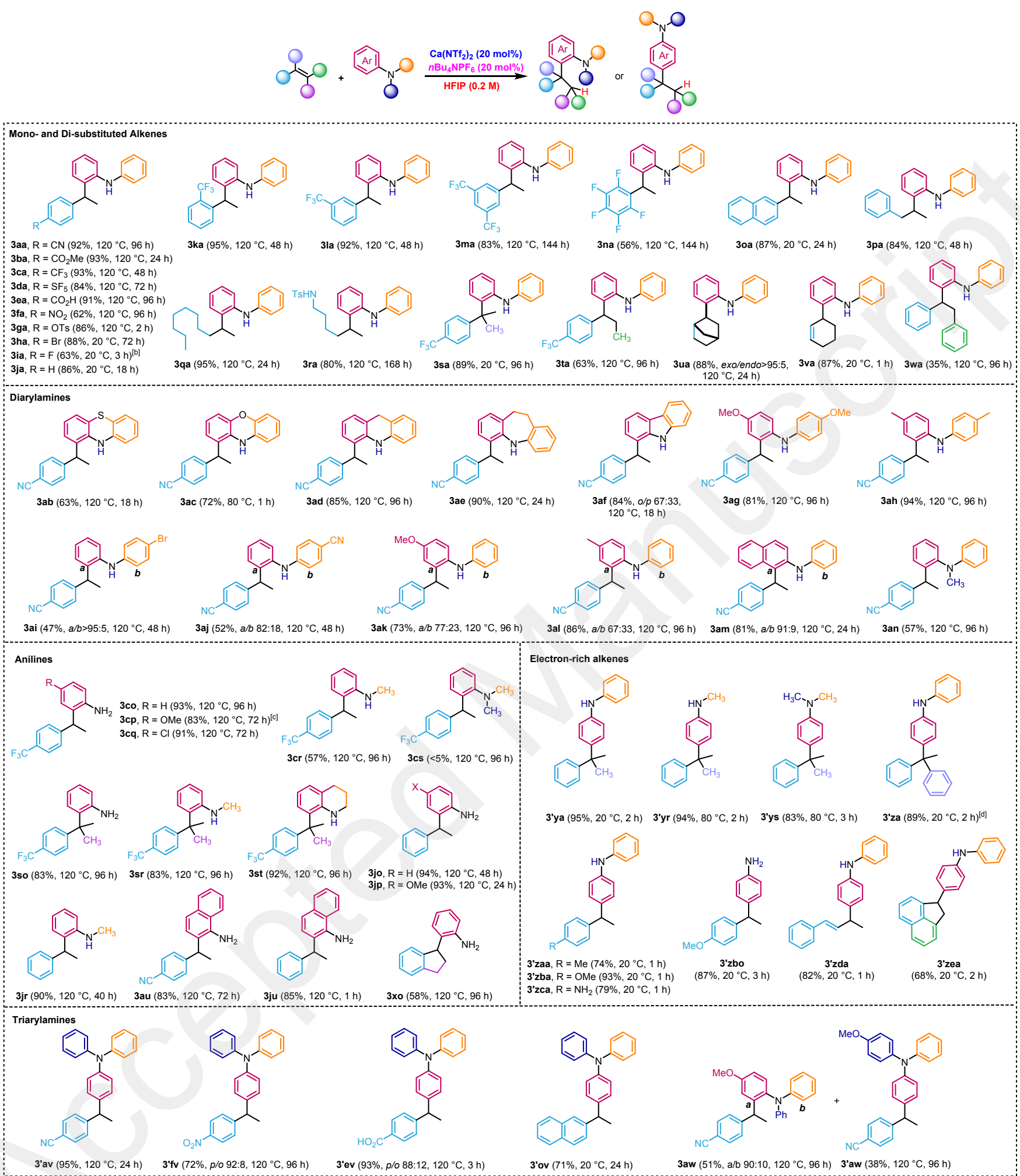

[a] Reactions performed in a sealed tube. [b] $o / p$ 88:12. [c] $o / N$ 93:7. [d] ortho-product obtained in 7\% yield.

ranging from 67:33 to $>95: 5$. Gratifyingly, engaging the tertiary diarylamine $\mathbf{2 n}$ in the reaction gave $3 \mathbf{a n}$ in $57 \%$ yield.

We also studied the title process with primary anilines, $\mathrm{N}$ alkyl anilines and 1-naphthylamine, which were previously found to form hydroamination products along the targeted compounds in well-documented Lewis and Brønsted acid catalysis. $^{6 a, 6 c-61,6 n}$ Here, they reacted with highly deactivated styrenes to generate exclusively ortho-products in high yields (up to 93\%). Similarly, the reaction between styrene and aniline derivatives afforded the targeted products (up to $94 \%$ ). One limitation of our method was the reactivity of a highly basic aniline such as $N, N$-dimethylaniline $2 \mathbf{s}$, which 
proved to be unreactive under standard reaction conditions. The results are in agreement with the hypothesized mechanism, where the reduced electrophilicity of the corresponding anilinium compared to those previously studied along with the low nucleophilicity of styrene 1c is prohibitive for the reaction to occur.

We noted that the electron density of the alkene is another key factor in this transformation. Indeed, when $\alpha$ methylstyrene $\mathbf{1 y}$ was employed instead of electrondeficient styrene 1s, we observed a complete switch of the selectivity from ortho to para, independently of the aniline used. These results hint at a different mechanism with electron-rich alkenes, which would first involve the protonation of the alkene with the formation of highly stable carbocation under the reaction conditions and a subsequent electrophilic aromatic substitution. Similarly, other electron-rich alkenes such as 1,1-diphenylethylene 1z, 4-methylstyrene 1za, 4-methoxystyrene 1zb, 4aminostyrene 1zc, (E)-1-phenyl-1,3-butadiene 1zd and acenaphthylene 1ze delivered the para-products in high yields (68-93\% yield). On the other hand, introducing an electron-withdrawing group on oxygen (1g) allows to restore the ortho-selectivity (3ga, 86\%). The use of triphenylamine $\mathbf{2 v}$ led also to the generation of paraadducts (3'av, 3'ev, $\mathbf{3}^{\prime} \mathbf{f v}$ and $\mathbf{3}$ 'ov) (71-95\% yields). Our assumption is that the reactivity of $\mathbf{2 v}$ might be directly linked to the $\mathrm{pKa}$ of its conjugated acid $\mathrm{Ph}_{3} \mathrm{NH}^{+}(\mathrm{pKa}=-3.9)$ in comparison to the ones of $\mathrm{Ph}_{2} \mathrm{NH}_{2}{ }^{+}(\mathrm{pKa}=0.8)$ and $\mathrm{PhNH}_{3}{ }^{+}(\mathrm{p} K a=4.6) .^{22}$ Indeed, $\mathrm{Ph}_{3} \mathrm{NH}^{+}$should protonate the alkene more easily than $\mathrm{Ph}_{2} \mathrm{NH}_{2}{ }^{+}$or $\mathrm{PhNH}_{3}{ }^{+}$and, in that case, an electrophilic aromatic substitution would occur. This trend could be partly counterbalanced through electronic effects by introducing an electron-donating group (4$\left.\mathrm{MeOPh}) \mathrm{Ph}_{2} \mathrm{NH}^{+}, \mathrm{pKa} \sim-2.4\right)^{23}$ to form the ortho-C-alkylated product 3 aw in $51 \%$ yield. However, we cannot exclude that the ortho-alkylation may also take place and that the increased stability of the carbocation intermediate may facilitate the retro-alkylation to eventually generate the more stable para-alkylated product. Indeed, when compound $3 \mathbf{z b o}^{6 \mathrm{~h}}$ was subjected to the reaction conditions, we observed its conversion into para-product 3'zbo, albeit in a moderate yield (57\%) (Scheme 3).

Scheme 3. Possibility of a rearrangement from ortho- to para-product.

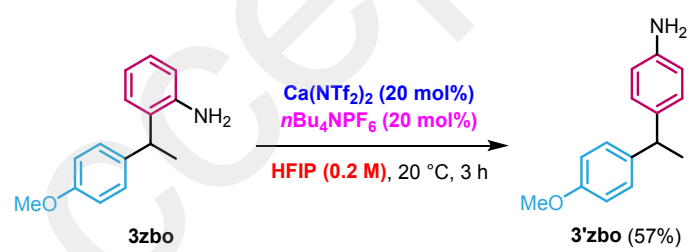

The overall excellent ortho-selectivities observed led us to examine in more detail the mechanism governing this transformation, notably its potentially concerted nature. As mentioned above, no isomerization product was obtained in the case of aliphatic alkenes, which seems in agreement with a plausible concerted mechanism for the formation of the targeted products. To confirm this hypothesis, we conducted the hydroarylation of allylbenzene 1p with 1,2dimethoxybenzene under standard conditions (Scheme 4), which delivered compound $\mathbf{3 p}$ as a major product, resulting from an isomerization/hydroarylation sequence in a typical proton-catalyzed process. On the other hand, when the same reaction was conducted in the presence of $\mathbf{2 a}$, the reaction provided $\mathbf{3 p a}$ as a sole product, while neither $\mathbf{3 p}$ nor 3'p was detected. Besides, when the protonation of the alkene occurred in the case of electron-rich alkenes, we noted that only the formation of the para-products was observed.

Scheme 4. Reactivity of aliphatic alkenes

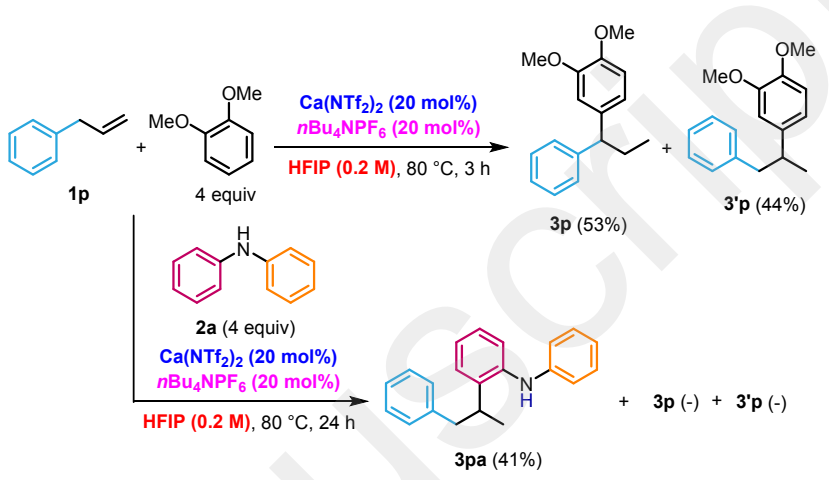

Secondly, although the hydroaminated adduct was not detected in the previous examples, we cannot rule out the possibility that a Hofmann-Martius rearrangement, ${ }^{24}$ which consists in the rearrangement of $N$-alkylated aniline into the ortho-C-alkylated aniline, occurred during the reaction. Indeed, in the case of norbornene $1 \mathbf{u}$, we could observe the formation of the hydroamination product $\mathbf{3}$ ' $\mathbf{u}$ along with 3uo (Scheme 5). Upon prolonged heating at $160{ }^{\circ} \mathrm{C}$, 3'uo could be mostly converted into 3uq (81\%). We also prepared in parallel the secondary amine $\mathbf{3}^{\text {"co }}{ }^{11 a}$ and subjected it to the reaction conditions. After 96 h, 3"co remained fully intact, indicating that this reaction pathway is unlikely to take place in the case of highly deactivated styrenes.

Scheme 5. Possibility of a Hofmann-Martius rearrangement.

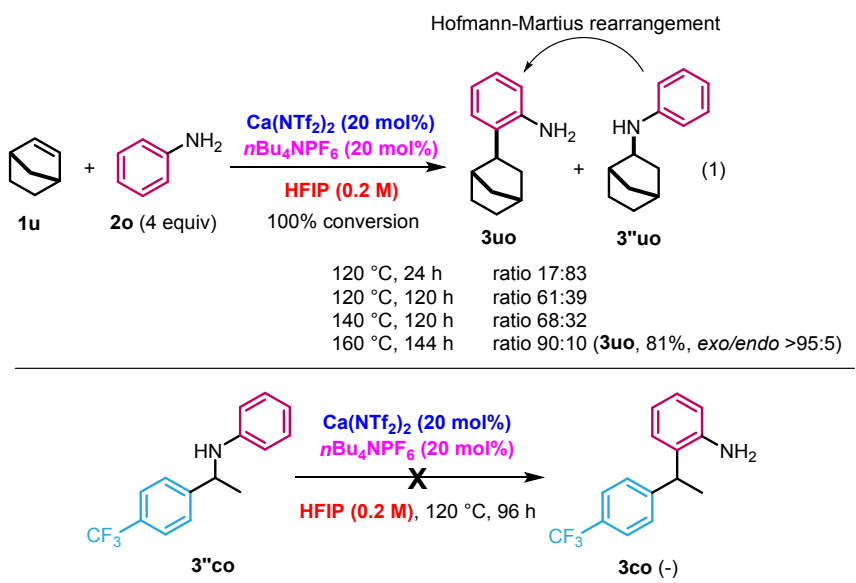

To shed more light on the reaction mechanism, we studied the reaction of aniline with styrene by DFT computations, performed at the M06-2X/6-311+G(d,p) level of theory. The values discussed below are Gibbs free energies at $393.15 \mathrm{~K}$ $\left(\Delta G_{393} \mathrm{kcal} / \mathrm{mol}\right)$, which include a solvent correction. A detailed discussion is presented in the Supporting 
Information and only the main conclusions are summarized here. As mentioned above, the $\mathrm{Ca}\left(\mathrm{NTf}_{2}\right)_{2} / n \mathrm{Bu}_{4} \mathrm{NPF}_{6}$ is likely to generate $\mathrm{Ca}\left(\mathrm{NTf}_{2}\right)\left(\mathrm{PF}_{6}\right){ }^{19}$ Thus, the $\mathrm{Ca}\left(\mathrm{NTf}_{2}\right)^{+}$ion has been used in the computations. In agreement with our previous computational studies on calcium-catalyzed reactions in alcoholic media, a direct activation of the substrates by $\mathrm{Ca}\left(\mathrm{NTf}_{2}\right)^{+}$proved to be inefficient. ${ }^{8 f, 14 a, 19 \mathrm{c}}$ Simple H-bonded (HFIP $)_{n}$ clusters $(n=1,2,3)$ also led to prohibitively high energy barriers. We then studied various combinations of $\mathrm{Ca}\left(\mathrm{NTf}_{2}\right)^{+}$and HFIP molecules (up to three). The lowest energy was obtained with one $\mathrm{Ca}\left(\mathrm{NTf}_{2}\right)^{+}$ and two HFIPs (Scheme 6). Once HFIP is ligated to the calcium center, its acidity is strengthened, and it spontaneously protonates aniline to give adduct $\mathbf{A} .^{25,26} \mathrm{~N}$-toC proton transfer requires $24.6 \mathrm{kcal} / \mathrm{mol}$ of free energy of activation. The resulting carbocation (not shown) collapses to the Wheland-type intermediate $\mathbf{B}$, located at 7.0 $\mathrm{kcal} / \mathrm{mol}$. The formation of $\mathbf{B}$ can thus be considered as nearly concerted. The deprotonation could be modeled directly from $\mathbf{B}$, but a lower energy path was obtained from the more stable isomer $\mathbf{C}$, lying at $-1.4 \mathrm{kcal} / \mathrm{mol}$ on the free energy surface. In C, it is HFIP that is bound to the ammonium instead of the calcium alcoholate. This new arrangement of the fragments benefits from a $\pi$-arene calcium interaction, ${ }^{27}$ which lowers the deprotonation barrier ([TS $\left.\left.\mathrm{TD}_{\mathrm{CD}}\right], 11.5 \mathrm{kcal} / \mathrm{mol}\right)$ and provides the final $\pi$ arene calcium complex $\mathbf{D}$, more stable than $\mathbf{A}$ by 19.5 $\mathrm{kcal} / \mathrm{mol}$.

Scheme 6. Simplified free energy profile $\left(\Delta G_{393}, \mathrm{kcal} / \mathrm{mol}\right)$ of the $\left[\mathrm{Ca}\left(\mathrm{NTf}_{2}\right)(\mathrm{HFIP})\right]^{+}$-triggered ortho- $C$-alkylation of aniline with styrene.

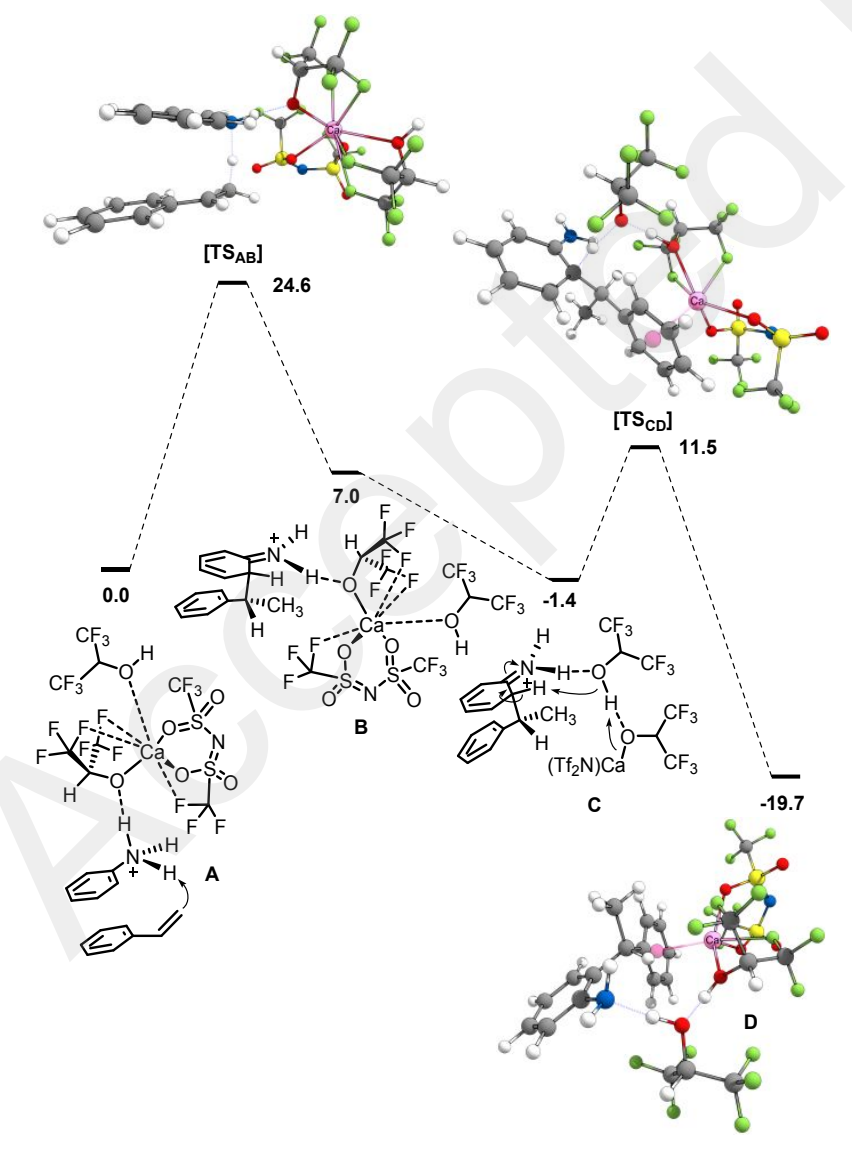

The $N$-alkylation was also calculated, and it was found to require $1.6 \mathrm{kcal} / \mathrm{mol}$ more free energy of activation than going to the ortho- $C$-alkylation transition state (see the Supporting Information). We can thus conclude that the $\mathrm{N}$ alkylation/Hofmann-Martius pathway, which could also explain the formation of the ortho- $C$-alkylation product, should be a minor process with aniline and styrene compared to the ortho-C-alkylation proposed in Scheme 5. It should also be noted that the para-alkylation transition state was found much higher in energy than $\left[\mathrm{TS}_{\mathrm{AB}}\right]$ (39.9 $\mathrm{kcal} / \mathrm{mol}$ ). Thus, at least with primary anilines, and in line with the experimental results, the para-alkylation seems unlikely compared to the ortho-alkylation pathway. Overall, this set of computations shows that the $\mathrm{Ca}\left(\mathrm{NTf}_{2}\right)^{+} / \mathrm{HFIP}$ mixture provides an acidic medium able to protonate aniline and facilitate a proton transfer to styrene which, although not thermodynamically favored, is triggered by the virtually concomitant formation of the $\mathrm{C}-\mathrm{C}$ bond and a facile deprotonation of the Wheland intermediate. This process can only take place in the ortho position, hence the regioselectivity observed with primary amines.

From a synthetic perspective, those compounds were engaged in several derivatizations to build useful frameworks that could be tedious to prepare otherwise (Scheme 7). Because the reaction of carbazole led to a mixture of products, we tested an approach to circumvent this issue. A simple Pd-catalyzed oxidative $\mathrm{C}-\mathrm{C}$ bond formation of 3aa gave access to carbazole 3af in 73\% yield. ${ }^{28}$ Another envisaged application was to engineer a

Scheme 7. Derivatizations of the ortho-C-alkylated compounds.
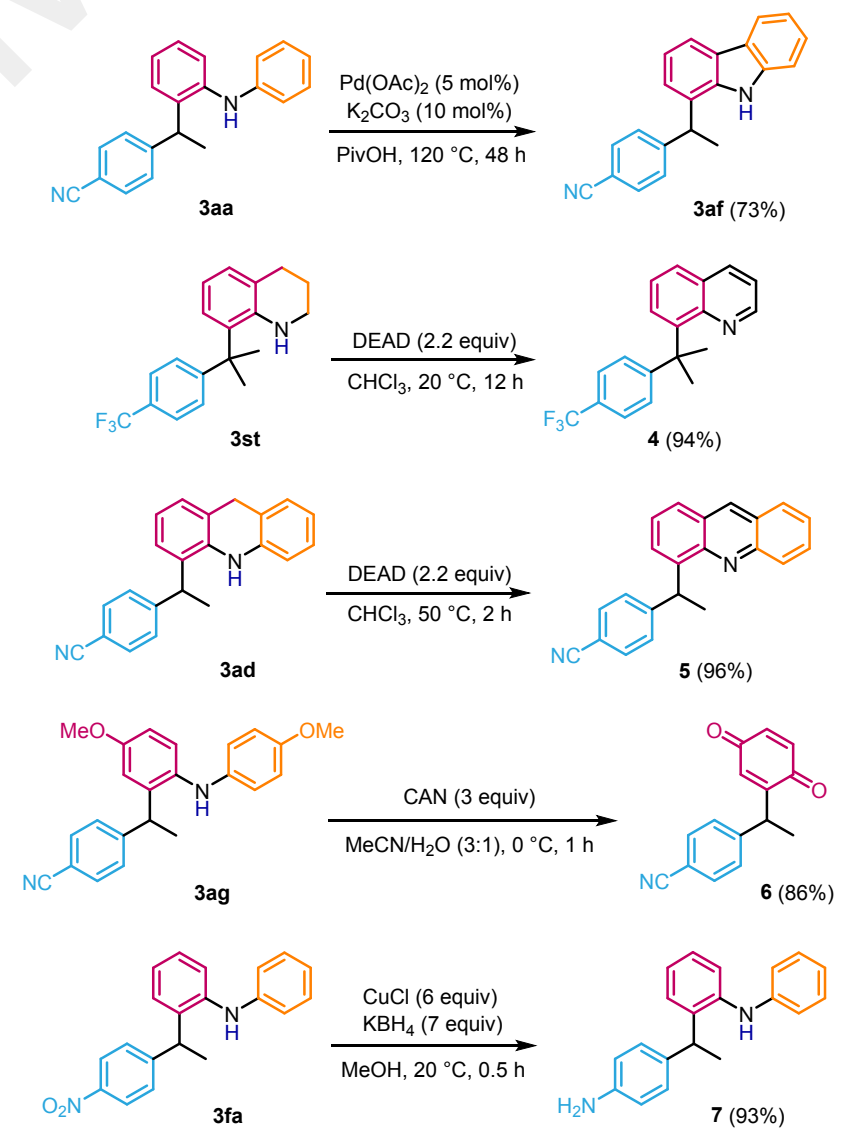
dehydrogenation of tetrahydroquinoline 3su and dihydroacridine $\mathbf{3 a d}$ in the presence of diethyl azodicarboxylate (DEAD). ${ }^{29}$ In this way, formal ortho-Calkylated products of quinoline (4) and acridine (5) were delivered in $94 \%$ and $96 \%$ yields, respectively. Of note, quinoline and acridine are unreactive under our standard conditions. In the same vein, because the benzylation of quinone is challenging, ${ }^{30}$ we used our strategy as a relay to access such type of products (6 in $86 \%$ yield) through the oxidation of 3ag in the presence of cerium ammonium nitrate (CAN). Moreover, the primary aniline 7 could be obtained by reduction of $\mathbf{3 f a}$ in $93 \%$ yield, ${ }^{31}$ while it could not be accessed starting from 4-aminostyrene 1zc.

In conclusion, we have devised a general and efficient method to accomplish the selective ortho-C-alkylation of aniline derivatives, which is enabled by the partnership of a Lewis acid and hexafluoroisopropanol as a solvent. This transformation displays broad functional group tolerance and high selectivities, while using inexpensive feedstocks. In contrast to previous strategies, this method is not only applicable to electron-rich and moderately electron-poor styrenes, but could also be extended to highly deactivated styrenes, aliphatic alkenes and dienes. It further buttresses the utility of hexafluoroisopropanol in organic synthesis to develop hitherto unsolved transformations. Additionally, we emphasized that the nature of the aniline and the alkene had a major impact on the ortho/para selectivity of the reaction.

\section{ASSOCIATED CONTENT}

\section{Supporting Information.}

Experimental procedures, characterization data and NMR spectra of all new compounds. This material is available free of charge via the Internet at http://pubs.acs.org/

\section{AUTHOR INFORMATION}

\section{Corresponding Authors}

* dleboeuf@unistra.fr

* vincent.gandon@universite-paris-saclay.fr

\section{Notes}

The authors declare no competing financial interest.

\section{ACKNOWLEDGMENT}

We gratefully thank the ANR (ANR-17-CE07-0003 funding for SW and ANR-16-CE07-0022 funding for GF), the CNRS, Ecole Polytechnique and Université Paris-Saclay for the support of this work. We used the OCCIGEN high performance cluster of the CINES.

\section{REFERENCES}

(1) (a) Lawrence S. A. Amines: Synthesis, Properties and Applications; Cambridge University Press: Cambridge, 2004. (b) The Chemistry of Anilines. Part 1; Rappoport, Z., Ed.; John Wiley \& Sons: New York, 2007; Vol. 1. (c) Amino Group Chemistry: From Synthesis to the Life Science; Ricci, A., Ed.; John Wiley \& Sons: New York, 2008.

(2) (a) Joshi-Pangu, A.; Lévesque, F.; Roth, H. G.; Oliver, S. F.; Campeau, L.-C.; Nicewicz, D. A.; DiRocco, D. A. Acridinium-Based Photocatalysts: A Sustainable Option in Photoredox Catalysis. J. Org. Chem. 2016, 81, 7244-7249. (b) Fischer, C.; Sparr, C. Direct
Transformation of Esters in Heterocyclic Fluorophores. Angew. Chem. Int. Ed. 2018, 57, 2436-2440.

(3) (a) Romero, N. A.; Nicewicz, D. A. Organic Photoredox Catalysis. Chem. Rev. 2016, 116, 10075-10166. (b) Magrey, K. A.; Nicewicz, D. A. A General Approach to Catalytic Alkene AntiMarkovnikov Hydrofunctionalization Reactions via Acridinium Photoredox Catalysis. Acc. Chem. Res. 2016, 49, 1997-2006.

(4) For reviews on hydroarylation of unactivated alkenes, see: (a) Rueping, M.; Nachtsheim, B. J. A Review of New Developments in the Friedel-Crafts Alkylation. Beilstein J. Org. Chem. 2010, 6, No. 6. (b) Andreatta, J. R.; McKeown, B. A.; Gunnoe, T. B. Transition Metal Catalyzed Hydroarylation of Olefins Using Unactivated Substrates: Recent Developments and Challenges. J. Organomet. Chem. 2011, 696, 305-315. (c) Dong, Z.; Ren, Z.; Thompson, S. J.; Xu, Y.; Dong, G. Transition-Metal-Catalyzed C-H Alkylation Using Alkenes. Chem. Rev. 2017, 117, 9333-9403. (d) Catalytic Hydroarylation of Carbon-Carbon Multiple Bonds; Ackermann, L., Gunnoe, B. T., Goj Habgood, L., Eds.; Wiley-VCH, 2018.

(5) For seminal reports, see: (a) Ecke, G. G.; Napolitano, J. P.; Filbey, A. H.; Kolka, A. J. ortho-Alkylation of Aromatic Amines. J. Org. Chem. 1957, 22, 639-642. (b) Stroh, R.; Ebersberger, J.; Haberland, H.; Hahn, W. Neuere Methoden der Präparativen Organischen Chemie II. 7. Alkyliering Aromatischer Amine. Angew. Chem. 1957, 69, 124-131.

(6) (a) Beller, M.; Thiel, O. R.; Trauthwein, H. Catalytic Alkylation of Aromatic Amines with Styrene in the Presence of Cationic Rhodium Complexes and Acid. Synlett 1999, 243-245. (b) Uchimaru, Y. N-H Activation vs. C-H Activation: RutheniumCatalysed Regioselective Hydroamination of Alkynes and Hydroarylation of an Alkene with $\mathrm{N}$-Methylaniline. Chem. Commun. 1999, 1133-1134. (c) Ackermann, L.; Kaspar, L. T.; Gschrei, C. J. $\mathrm{TiCl}_{4}$-Catalyzed Intermolecular Hydroamination Reactions of Norbornene. Org. Lett. 2004, 6, 2515-2518. (d) Kaspar, L. T.; Fingerhut, B.; Ackermann, L. Titanium-Catalyzed Intermolecular Hydroamination of Vinylarenes. Angew. Chem. Int. Ed. 2005, 44, 5972-5974. (e) Cherian, A. E.; Domski, G. J.; Rose, J. M.; Lobkovsky, E. B.; Coates, G. W. Acid-Catalyzed ortho-Alkylation of Anilines with Styrenes: An Improved Route to Chiral Anilines with Bulky Substitutents. Org. Lett. 2005, 7, 5135-5137. (f) Anderson, L. L.; Arnold, J.; Bergman, R. G. Proton-Catalyzed Hydroamination and Hydroarylation Reactions of Anilines and Alkenes: A Dramatic Effect of Counteranions on Reaction Efficiency. J. Am. Chem. Soc. 2005, 127, 14542-14543. (g) Lapis, A. A. M.; DaSilveira Neto, B. A.; Scholten, J. D.; Nachtigall, F. M.; Eberlin, M. N.; Dupont, J. Intermolecular Hydroamination and Hydroarylation Reactions of Alkenes in Ionic Liquids. Tetrahedron Lett. 2006, 47, 6775-6779. (h) Marcseková, K.; Doye, S. HI-Catalyzed Hydroamination and Hydroarylation of Alkenes. Synthesis 2007, 145-154. (i) Wei, H.; Qian, G.; Xia, Y.; Li, K.; Li, W. $\mathrm{BiCl}_{3}$-Catalyzed Hydroamination of Norbornene with Aromatic Amines. Eur. J. Org. Chem. 2007, 44714474. (j) Prades, A.; Corberán, R.; Poyatos, M.; Peris, E. A simple Catalyst for the Efficient Benzylation of Arenes by Using Alcohols, Ethers, Styrenes, Aldehydes, or Ketones. Chem. Eur. J. 2009, 15, 4610-4613. (k) Babu, N. S.; Reddy, K. M.; Prasad, P. S.; Suryanarayana, I.; Lingaiah, N. Intermolecular Hydroamination of Vinyl Arenes Using Tungstophoric Acid as a Simple and Efficient Catalyst. Tetrahedron Lett. 2007, 48, 7642-7645. (l) Liu, G.-Q.; Li, Y.-M. Zinc Triflate-Catalyzed Intermolecular Hydroamination of Vinylarenes and Anilines: Scopes and Limitations. Tetrahedron Lett. 2011, 52, 7168-7170. (m) Hu, X.; Martin, D.; Melaimi, M.; Bertrand, G. Gold-Catalyzed Hydroarylation of Alkenes with Dialkylanilines. J. Am. Chem. Soc. 2014, 136, 13594-13597. (n) Pérez, M.; Mahdi, T.; Hounjet, L. J.; Stephan, D. W. Electrophilic Phosphonium Cations Catalyze Hydroarylation and Hydrothiolation of Olefins. Chem. Commun. 2015, 51, 1130111304. (o) Crisenza, G. E. M.; Sokolova, O. O.; Bower, J. F. BranchSelective Alkene Hydroarylation by Cooperative Destabilization: Iridium-Catalyzed ortho-Alkylation of Acetanilides. Angew. Chem. Int. Ed. 2015, 54, 14866-14870. (p) Song, G.; Luo, G.; Oyamada, J.; 
Luo, Y.; Hou, Z. ortho-Selective $\mathrm{C}-\mathrm{H}$ Addition of $\mathrm{N}, \mathrm{N}$-Dimethyl Anilines to Alkenes by a Yttrium Catalyst. Chem. Sci. 2016, 7, 52655270. (q) Abdellah, I.; Poater, A.; Lohier, J.-F.; Gaumont, A.-C. Au(I)Catalyzed Hydroarylation of Alkenes with $N, N$-Dialkylanilines: A Dual Gold Catalysis Concept. Catal. Sci. Technol. 2018, 8, 64866492. (r) Zhu, W.; Sun, Q.; Wang, Y.; Yuan, D.; Yao, Y. Chemo- and Regioselective Hydroarylation of Alkenes with Aromatic Amines Catalyzed by $\left[\mathrm{Ph}_{3} \mathrm{C}\right]\left[\mathrm{B}\left(\mathrm{C}_{6} \mathrm{H}_{5}\right)_{4}\right]$. Org. Lett. 2018, 20, 3101-3104. (s) Schroeter, F.; Lerch, S.; Kaliner, M.; Strassner, T. Cobalt-Catalyzed Hydroarylations and Hydroaminations of Alkenes in Tunable Aryl Alkyl Ionic Liquids. Org. Lett. 2018, 20, 6215-6219. (t) Grélaud, S.; Cooper, P.; Feron, L. J.; Bower, J. F. Branch-Selective and Enantioselective Iridium-Catalyzed Alkene Hydroarylation via Anilide-Directed C-H Oxidative Addition. J. Am. Chem. Soc. 2018, 140, 9351-9356. (u) Rank, C. K.; Özkaya, B.; Patureau, F. W. HBF ${ }_{4}^{-}$ and $\mathrm{AgBF}_{4}$-Catalyzed ortho-Alkylation of Diarylamines and Phenols. Org. Lett. 2019, 21, 6830-6834. (v) Su, J.; Cai, Y.; Xu, X. Scandium-Catalyzed para-Selective Alkylation of Aromatic Amines with Alkenes. Org. Lett. 2019, 21, 9055-9059.

(7) For a related example involving benzylic alcohols instead of styrenes, see: Meng, S.-S.; Tang, X.; Luo, X.; Wu, R.; Zhao, J.-L. Chan, A. S. C. Borane-Catalyzed Chemoselectivity-Controllable NAlkylation and ortho C-Alkylation of Unprotected Arylamines Using Benzylic Alcohols. ACS. Catal. 2019, 9, 8397-8403.

(8) Fore rare examples of hydroarylation involving highly deactivated styrenes but not anilines, see: (a) Kischel, J.; Jovel, I.; Mertins, K.; Zapf, A.; Beller, M. A Convenient $\mathrm{FeCl}_{3}$-Catalyzed Hydroarylation of Styrenes. Org. Lett. 2006, 8, 19-22. (b) Gligorich, K. M.; Cummings, S. A.; Sigman, M. S. Palladium-Catalyzed Reductive Coupling of Styrenes and Organostannanes under Aerobic Conditions. J. Am. Chem. Soc. 2007, 129, 14193-14195. (c) Semba, K.; Ariyama, K.; Zheng, H.; Kameyama, R.; Sakaki, S.; Nakao, Y. Reductive Cross-Coupling of Conjugated Arylalkenes and Aryl Bromides with Hydrosilanes by Cooperative Palladium/Copper Catalysis. Angew. Chem. Int. Ed. 2016, 55, 6275-6279. (d) Friis, S. D.; Pirnot, M. T.; Buchwald, S. L. Asymmetric Hydroarylation of Vinylarenes Using a Synergestic Combination of $\mathrm{CuH}$ and $\mathrm{Pd}$ Catalysis. J. Am. Chem. Soc. 2016, 138, 8372-8375. (e) Xiao, L.-J.; Cheng, L.; Feng, W.-M.; Li, M.-L.; Xie, J.-H.; Zhou, Q.-L. Nickel(0)Catalyzed Hydroarylation of Styrenes and 1,3-Dienes with Organoboron Compounds. Angew. Chem. Int. Ed. 2018, 57, 461464. (f) Qi, C.; Gandon, V.; Lebœuf, D. Calcium(II)-Catalyzed Intermolecular Hydroarylation of Deactivated Styrenes in Hexafluoroisopropanol. Angew. Chem. Int. Ed. 2018, 57, 1424514249. (g) Chen, Y.-G.; Shuai, B.; Xu, X.-T.; Li, Y.-Q.; Yang, Q.-L.; Qiu, H.; Zhang, K.; Fang, P.; Mei, T.-S. Nickel-Catalyzed Enantioselective Hydroarylation and Hydroalkenylation of Styrenes. J. Am. Chem. Soc. 2019, 141, 3395-3399. (h) Wang, G.; Gao, L.; Chen, H.; Liu, H.; Chen, S.; Cheng, X.; Li, S. Chemoselective Borane-Catalyzed Hydroarylation of 1,3-Dienes with Phenols. Angew. Chem. Int. Ed. 2019, 58, 1694-1699.

(9) Meyer, M. A.; Castellano, R. K.; Diederich, F. Interactions with Aromatic Rings in Chemical and Biological Recognition. Angew. Chem. Int. Ed. 2003, 42, 1210-1250.

(10) (a) Müller, T. E.; Hultzsch, K. C.; Yus, M.; Foubelo, F.; Tada, M. Hydroamination: Direct Addition of Amines to Alkenes and Alkynes. Chem. Rev. 2008, 108, 3795-3892. (b) Huang, L.; Arndt, M.; Gooßen, K.; Heydt, H.; Gooßen, L. J. Late Transition-Metal-Catalyzed Hydroamination and Hydroamidation. Chem. Rev. 2015, 115, 25962697. (c) Bernoud, E.; Lepori, C.; Mellah, M.; Schulz, E.; Hannedouche, J. Recent Advances in Metal-Free and Late Transition Metal-Catalysed Hydroamination of Unactivated Alkenes. Catal. Sci. Technol. 2015, 5, 2017-2037. (d) Reznichenko, A. L.; Hultzsch, K. C. Hydroamination of Alkenes. In Organic Reactions; Denmark, S. E., Ed.; Wiley \& Sons: New York, 2015; Vol. 88.

(11) For selected examples, see: (a) Kawatsura, M.; Hartwig, J. F. Palladium-Catalyzed Intermolecular Hydroamination of Vinylarenes Using Arylamines. J. Am. Chem. Soc. 2000, 122, 9546-
9547. (b) Minami, T.; Okamoto, H.; Ikeda, S.; Tanaka, R.; Ozawa, F.; Yoshifuji, M. ( $\eta^{3}$-Allyl)palladium Complexes Bearing Diphosphonidenecyclobutene Ligands: Highly Active Catalysts for the Hydroamination of 1,3-Dienes. Angew. Chem. Int. Ed. 2001, 40, 4501-4503. (c) Johns, A. M.; Utsunomiya, M.; Incarvito, C. D.; Hartwig, J. F. A Highly Active Palladium Catalyst for Intermolecular Hydroamination. Factors that Control Reactivity and Additions of Functionalized Anilines to Dienes and Vinylarenes. J. Am. Chem. Soc. 2006, 128, 1828-1839. (d) Johns, A. M.; Sakai, N.; Ridder, A.; Hartwig, J. F. Direct Measurement of the Thermodynamics of Vinylarene Hydroamination. J. Am. Chem. Soc. 2006, 128, 93069307. (e) Yang, X.-H.; Dong, V. M. Rhodium-Catalyzed Hydrofunctionalization: Enantioselective Coupling of Indolines and 1,3-Dienes. J. Am. Chem. Soc. 2017, 139, 1774-1777.

(12) Xiong, Y.; Zhang, G. Visible-Light-Induced Copper-Catalyzed Intermolecular Markovnikov Hydroamination of Alkenes. Org. Lett. 2019, 21, 7873-7877.

(13) For reviews on HFIP, see: (a) Bégué, J.-P.; Bonnet-Delpon, D.; Crousse, B. Fluorinated Alcohols: A New Medium for Selective and Clean Reaction. Synlett 2004, 18-29. (b) Shuklov, I. A.; Dubrovina, N. V.; Börner, A. Fluorinated Alcohols as Solvents, Cosolvents and Additives in Homogeneous Catalysis. Synthesis 2007, 2925-2943. (c) Sugiishi, T.; Matsugi, M.; Hamamoto, H.; Amii, H. Enhancement of Stereoselectivities in Asymmetric Synthesis Using Fluorinated Solvents, Auxiliaries, and Catalysts. RSC Adv. 2015, 5, 17269-17282. (d) Wencel-Delord, J.; Colobert, F. A Remarkable Solvent Effect of Fluorinated Alcohols on Transition Metal Catalysed C-H Functionalizations. Org. Chem. Front. 2016, 3, 394-400. (e) Colomer, I.; Chamberlain, A. E. R.; Haughey, M. B.; Donohoe, T. J. Hexafluoroisopropanol as a Highly Versatile Solvent. Nat. Rev. Chem. 2017, 1, 0088. (f) Sinha, S. K.; Bhattacharya, T.; Maiti, D. Role of Hexafluoroisopropanol in $\mathrm{C}-\mathrm{H}$ Activation. React. Chem. Engl. 2019, 4, 244-253.

(14) (a) Qi, C.; Hasenmaile, F.; Gandon, V.; Lebœuf, D. Calcium(II)-Catalyzed Intra- and Intermolecular Hydroamidation of Unactivated Alkenes in Hexafluoroisopropanol. ACS Catal. 2018, 8, 1734-1739. (b) Qi, C.; Yang, S.; Gandon, V.; Lebœuf, D. Calcium(II)- and Triflimide-Catalyzed Intramolecular Hydroacyloxylation of Unactivated Alkenes in Hexafluoroisopropanol. Org. Lett. 2019, 21, 7405-7409.

(15) For recent examples of enhancement of reactivity via the use of HFIP and a comprehensive understanding, see: (a) Berkessel, A.; Adrio, J. A.; Hüttenhain, D.; Neudörfl, J. M. Unveiling the "Booster Effect" of Fluorinated Alcohol Solvents: AggregationInduced Conformational Changes and Cooperatively Enhanced HBonding. J. Am. Chem. Soc. 2006, 128, 8421-8426. (b) Berkessel, A.; Adrio, J. A. Dramatic Acceleration of Olefin Epoxidation in Fluorinated Alcohols: Activation of Hydrogen Peroxide by Multiple H-Bond Networks. J. Am. Chem. Soc. 2006, 128, 13412-13420. (c) Motiwala, H. F.; Fehl, C.; Li, S.-W.; Hirt, E.; Porubsky, P.; Aubé, J. Overcoming Product Inhibition in Catalysis of the Intramolecular Schmidt Reaction. J. Am. Chem. Soc. 2013, 135, 9000-9009. (d) Colomer, I.; Batchelor-McAuley, C.; Odell, B.; Donohoe, T. J.; Compton, R. G. Hydrogen Bonding to Hexafluoroisopropanol Controls the Oxidative Strength of Hypervalent Iodine Reagents. J. Am. Chem. Soc. 2016, 138, 8855-8861. (e) Vukovic, V. D.; Richmond, E.; Wolf, E.; Moran, J. Catalytic Friedel-Crafts Reactions of Highly Electronically Deactivated Benzylic Alcohols. Angew. Chem. Int. Ed. 2017, 56, 3085-3089. (f) Conway, Jr. J. H.; Rovis, T. Regiodivergent Iridium(III)-Catalyzed Diamination of Alkenyl Amides with Secondary Amines: Complementary Access to $\gamma$ - or $\delta$-Lactams. J. Am. Chem. Soc. 2018, 140, 135-138. (g) Tao, Z.; Robb, K. A.; Zhao, K.; Denmark, S. E. Enantioselective, Lewis Base-Catalyzed Sulfenocyclization of Polyenes. J. Am. Chem. Soc. 2018, 140, 3569 3573. (h) Richmond, E.; Yi, J.; Vukovic, V. D.; Sajadi, F.; Rowley, C. N.; Moran, J. Ring-Opening Hydroarylation of Monosubstituted Cyclopropanes Enabled by Hexafluoroisopropanol. Chem. Sci. 2018, 9, 6411-6416. (i) Qin, Q.; Xie, Y.; Floreancig, P. E. Diarylmethane Synthesis through $\mathrm{Re}_{2} \mathrm{O}_{7}$-Catalyzed Bimolecular 
Dehydrative Friedel-Crafts Reactions. Chem. Sci. 2018, 9, 85288533. (j) Bernhardt, A.; Kelm, H.; Patureau, F. W. The Strong $\beta-\mathrm{CF}_{3}$ Shielding Effect in Hexafluoroisopropanol and 100 Other Organic Solvents Revisited with ${ }^{17} \mathrm{O}$ NMR Spectroscopy. ChemCatChem. 2018, 10, 1547-1551. (k) D'Amato, E. M.; Borgel, J.; Ritter, T. Aromatic C-H Amination in Hexafluoroisopropanol. Chem. Sci. 2019, 10, 2424-2428. (l) Zhou, Z.; Cheng, Q.-Q.; Kürti, L. AzaRubottom Oxidation: Synthetic Access to Primary $\alpha$ Aminoketones. J. Am. Chem. Soc. 2019, 141, 2242-2246. (m) Y. Zhu, I. Colomer, A. L. Thompson, T. J. Donohoe. HFIP Solvent Enables Alcohols to Act as Alkylating Agents in Stereoselective Heterocyclization. J. Am. Chem. Soc. 2019, 141, 6489-6493. (n) Chatupheeraphat, A.; Rueping, M.; Magre, M. Chemo- and Regioselective Magnesium-Catalyzed ortho-Alkenylation of Anilines. Org. Lett. 2019, 21, 9153-9157. (o) Nielsen, C. D.-T.; White, A. J. P.; Sale, D.; Bures, J.; Spivey, A. C. Hydroarylation of Alkenes by Protonation/Friedel-Crafts Trapping: HFIP-Mediated Access to Per-aryl Quaternary Stereocenters. J. Org. Chem. 2019, 84, 14965-14973 (p) Wang, S.; Guillot, R.; Carpentier, J.-F.; Sarazin, Y.; Bour, C.; Gandon, V.; Lebœuf, D. Synthesis of Bridged Tetrahydrobenzo[b]azepines and Derivatives through an AzaPiancatelli cyclization/Michael Addition Sequence. Angew. Chem. Int. Ed. 2020, 59, 1134-1138.

(16) Kuznetsov, D. M.; Tumanov, V. V.; Smit, W. A. Cationic Polymerization of Styrenes under Essentially Neutral Conditions. J. Polym. Res. 2013, 20, 128-133.

(17) During the preparation of this manuscript, Colomer reported the hydroarylation of electron-rich alkenes with anilines. The overall transformation and key to reactivity (HFIP) are the same, but our catalyst furnishes complementary regioselectivity. Colomer, I. ACS Catal. 2020, 10, 6023-6029. Besides, we tested his catalytic system (NaOAc in HFIP) in our model reaction between 1a and $2 a$ and we did not observe any reactivity.

(18) For reviews on Ca(II) catalysis, see: (a) Begouin, J.-M.; Niggemann, M. Calcium-Based Lewis Acid Catalysts. Chem. Eur. J. 2013, 19, 8030-8041. (b) Lebœuf, D.; Gandon, V. Carbon-Carbon and Carbon-Heteroatom Bond-Forming Transformations Catalyzed by Calcium(II) Triflimide. Synthesis 2017, 49, 15001508. (c) Rauser, M.; Schröder, S.; Niggemann, M. In Early Main Group Metal Catalysis: Concepts and Reactions; Harder, S., Ed.; Wiley-VCH, 2020, pp279-310.

(19) (a) Haubenreisser, S.; Niggemann, M. Calcium-Catalyzed Direct Amination of $\pi$-Activated Alcohols. Adv. Synth. Catal. 2011, 353, 469-474. (b) Davies, J.; Leonori, D. The First Calcium-Catalysed Nazarov Cyclisation. Chem. Commun. 2014, 50, 15171-15174; (c) Lebœuf, D.; Marin, L.; Michelet, B.; Perez-Luna, A.; Guillot, R.; Schulz, E.; Gandon, V. Harnessing the Lewis Acidity of HFIP Through its Cooperation with a Calcium(II) Salt: Application to the Aza-Piancatelli Reaction. Chem. Eur. J. 2016, 22, 16165-16171.

(20) Although diphenylamine $\mathbf{2 a}$ was used in excess (4 equivalents), it could be easily recovered by flash column chromatography during the purification of the crude material.

(21) The reaction was also attempted with activated alkenes such as ethyl acrylate but led only to the aza-Michael addition product.

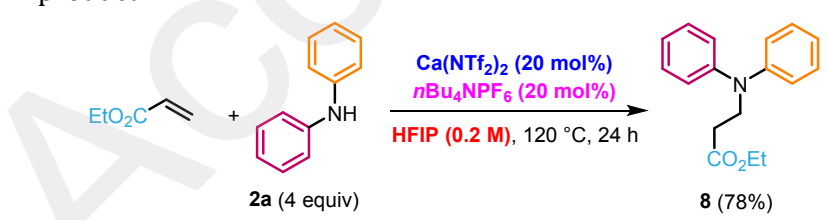

(22) For those $\mathrm{pKa}$ values, see: Kaljurand, I.; Lilleorg, R.; Murumaa, A.; Mishima, M.; Burk, P.; Koppel, I.; Koppel, I. A.; Leito, I. The Basicity of Substituted $N, N$-Dimethylanilines in Solution and in the Gas Phase. J. Phys. Org. Chem. 2013, 26, 171-181.

(23) Calculated using Advanced Chemistry Development (ACD/Labs) Software V11.02 (C) 1994-2020 ACD/Labs).

(24) (a) Hofmann, A. W.; Martius, C. A. Methylirung der Phenylgruppe im Anilin. Ber. Dtsch. Chem. Ges. 1871, 4, 742. (b)
Reilly, J.; Hickinbottom, W. J. Intramolecular Rearrangement of the Alkylarylamines: Formation of 4-Amino- $n$-butylbenzene. J. Chem. Soc., Trans. 1920, 117, 103-137.

(25) In our attempts to determine the reactive species, we performed NMR studies, which suggests the formation of $\mathrm{Ca}\left(\mathrm{NTf}_{2}\right)\left(\mathrm{OCH}\left(\mathrm{CF}_{3}\right)_{2}\right)$ when mixing $\mathrm{Ca}\left(\mathrm{NTf}_{2}\right)\left(\mathrm{PF}_{6}\right)$, HFIP and aniline (see Supporting Information for details).

(26) For the stabilization of calcium salts via $\mathrm{Ca} \cdots \mathrm{F}$ interactions, see: (a) Sarazin, Y.; Liu, B.; Roisnel, T.; Maron, L.; Carpentier, J.-F. Discrete, Solvent-Free Alkaline-Earth Metal Cations: Metal $\cdots$ Fluorine Interactions and ROP Catalytic Activity. J. Am. Chem. Soc. 2011, 133, 9069-9087. (b) Rosca, S.-C.; Roisnel, T.; Dorcet, V.; Carpentier, J.-F.; Sarazin, Y. Potassium and Well-Defined Neutral and Cationic Calcium Fluoroalkoxide Complexes: Structural Features and Reactivity. Organometallics 2014, 33, 5630-5644. (c) Sarazin, Y.; Carpentier, J.-F. Calcium, Strontium and Barium Homogeneous Catalysts for Fine Chemical Synthesis. Chem. Rec. 2016, 16, 2482-2505. (d) Sarazin, Y.; Carpentier, J.-F. In Noncovalent Interactions in Catalysis; Mahmudov, K. T.; Kopylovich, M. N.; Guedes da Silva, M. F. C.; Pombeiro, A. J. L., Eds.; RSC, 2019, pp94-121.

(27) (a) Buchanan, W. D.; Allis, D. G.; Ruhlandt-Senge, K. Synthesis and Stabilization-Advances in Organoalkaline Earth Metal Chemistry. Chem. Commun. 2010, 46, 4449-4465. (b) Causero, A.; Ballmann, G.; Pahl, J.; Zijlstra, H.; Färber, C.; Harder, S. Stabilization of Calcium Hydride Complexes by Fine Tuning of Amidinate Ligands. Organometallics 2016, 35, 3350-3360. (c) Pahl, J.; Brand, S.; Elsen H.; Harder, S. Highly Lewis Acidic Cationic Alkaline Earth Metal Complexes. Chem. Commun. 2018, 54, 86858688. (d) Garcia, L.; Anker, M. D.; Mahon,M. F.; Maron, L.; Hill, M. S. Coordination of Arenes and Phosphines by Charge Separated Alkaline Earth Cations. Dalton Trans. 2018, 47, 12684-12693. (e) Wilson, A. S. S.; Hill, M. S.; Mahon. M. F. Calcium Hydride Insertion Reactions with Unsaturated C-C Bonds. Organometallics 2019, 38, 351-360. (f) Garcia, L.; Mahon, M. F.; Hill, M. S. Multimetallic Alkaline-Earth Hydride Cations. Organometallics 2019, 38, 37783785. (g) Schorpp, M.; Krossing, I. Soft Interactions with Hard Lewis Acids: Generation of Mono- and Dicationic Alkaline-Earth Metal Arene-Complexes by Direct Oxidation. Chem. Sci. 2020, 11, 2068-2076.

(28) Liégault, B.; Lee, M.; Huestis, M. P. Stuart, D. R.; Fagnou, K. Intermolecular Pd(II)-Catalyzed Oxidative Biaryl Synthesis Under Air: Reaction Development and Scope. J. Org. Chem. 2008, 73, 50225028.

(29) Bang, S. B.; Kim, J. Efficient Dehydrogenation of 1,2,3,4Tetrahydroquinolines Mediated by Dialkyl Azodicarboxylates. Synth. Commun. 2018, 48, 1291-1298.

(30) Xu, X.-L.; Li, Z. Catalytic Electrophilic Alkylation of $p$ Quinones through a Redox Chain Reaction. Angew. Chem. Int. Ed. 2017, 56, 8196-8200.

(31) He, Y.; Zhao, H.; Pan, X.; Wang, S. Reduction with Metal Borohydride-Transition Metal Salt System. I. Reduction of Aromatic Nitro Compounds with Potassium BorohydrideCopper(I) Chloride. Synth. Commun. 1989, 19, 3047-3050. 


\section{SYNOPSIS TOC}

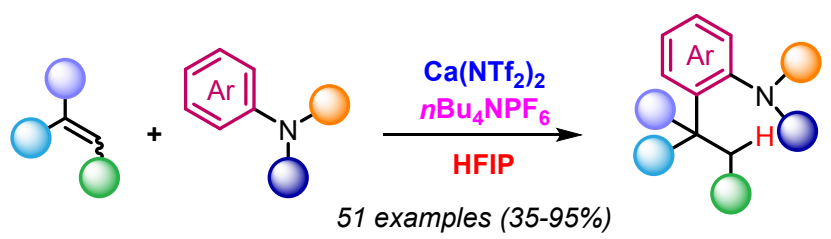

- Excellent ortho-C selectivity

- Use of previously unreactive substrates

- High yields and gram-scale

- Functional group tolerance

- Mechanism supported by DFT computations 